\title{
A STUDY ON CLINICAL, LABORATORY PROFILE AND OUTCOME OF DENGUE FEVER
}

Vanamali D.R ${ }^{1}$, L. Venugopal2 ${ }^{2}$ P. Yeshwanth³ ${ }^{3}$ Dilip Rampure ${ }^{4}$

HOW TO CITE THIS ARTICLE:

Vanamali D.R, L. Venugopal, P. Yeshwanth, DilipRampure. "A Study On Clinical, Laboratory Profile And Outcome Of Dengue Fever". Journal of Evolution of Medical And Dental Sciences 2013; Vol2, Issue 50, December 16; Page: 9739-9743.

ABSTRACT: BACKGROUND AND OBJECTIVES: In recent days there is an alarming increase in the incidence of dengue fever and has emerged as a serious international public health threat with almost half of the world's population at risk for infection. Very few studies have been conducted in this part of our country and hence this study was undertaken to study the clinical picture, laboratory profile and outcome of dengue fever in and around khammam. MATERIALS AND METHODS:A prospective study was conducted over one year at Mamata General Hospital, during which 190 cases were diagnosed as dengue fever which were taken into study and evaluated for clinical, laboratory profile and their outcome. RESULTS: Out of 190 patients taken into study, fever was the most common presentation followed by headache. Thrombocytopenia was seen in $75 \%$ of the patients. Bleeding manifestations were seen in patients with platelet counts less than $40000 / \mathrm{mm}^{3}$. 18 patients were diagnosed as DHF, 6 patients were diagnosed as DSS. During our study 10 patients expired. CONCLUSION: The clinical and hematological picture of dengue fever is like any other viral fevers and the bleeding manifestations are seen in patients whose platelet counts decreases less than $40000 / \mathrm{mm}^{3}$ only.

INTRODUCTION: Dengue is a fast emerging pandemic viral disease in many parts of the world especially in tropical and subtropical countries. In recent days there has been an alarming increase in the incidence of dengue fever and has emerged as a serious international public health threat with almost half of the world's population at risk for infection. The disease is also endemic in many parts of India, especially the metropolitan cities and towns. Outbreaks are now reported quite frequently from different parts of the country like rural areas of Haryana, Maharashtra, Andhra Pradesh and Karnataka.At present, information on adult dengue infections in South Asia is quite limited. Very few studies have been conducted in this part of our country and hence this study was undertaken to study the clinical picture, laboratory profile and outcome of dengue fever in and around khammam.

METHODS \& MATERIALS: A prospective study was conducted at a tertiary care hospital Mamata General Hospital, Khammam over duration of one year i.e. from May 2012 to April 2013. Patients above 18 years of age presenting with an acute febrile illness of 2-7 days duration with 2 or more of the following: headache, retro-orbital pain, myalgia, arthralgia, rash, haemorrhagic manifestations, leucopenia as per WHO IDSP criteria were evaluated for dengue.

Dengue fever was confirmed with Dengue day 1 test (J. Mitra \& Co. Pvt. Ltd.), which was a rapid solid phase immune-chromatographic test for the qualitative detection of Dengue NS1 antigen and differential detection of IgM and IgG antibodies to dengue virus in human serum/ plasma. This 
test has sensitivity of $100 \%$ and specificity of $99.94 \%$ for NS1Ag and $99.88 \%$ for IgM/ IgG antibodies.

Patients diagnosed with dengue fever/DHF / DSS as per IDSP criteria ${ }^{1}$ were taken into study and their data collected were clinical, laboratory, hematological,fever profile and mortality rate.

RESULTS:A total of 190 patients fulfilled inclusion and exclusion criteria and included in the study. Out of which 116 were male and 74 were female. The mean duration of fever prior to admission was 4 days. Apart from fever, headache (85\%) was the most frequent symptom at admission followed by myalgia (65\%). Abdominal pain was noted in 45\% patients; vomiting and dizziness were also common but found in less than $50 \%$ of the patients. Hepatomegaly was seen in 26 patients (14\%).18 patients were found to have bleeding manifestations.

\begin{tabular}{|l|c|}
\hline \multicolumn{1}{|c|}{ Symptoms } & Percentage \\
\hline Fever & 100 \\
\hline Headache & 85 \\
\hline Myalgia & 65 \\
\hline Joint pains & 58 \\
\hline Abdominal pain & 45 \\
\hline Vomiting & 42 \\
\hline Dizziness & 38 \\
\hline Skin rash & 27 \\
\hline Flushing & 20 \\
\hline
\end{tabular}

Table 1 showing clinical profile

We categorized the patients into six groups based on the platelets counts as mentioned in figure 1.

In our study thrombocytopenia was seen in $75 \%$ of the patients, $30 \%$ of patients had a platelet count below $40000 / \mathrm{mm}^{3}$, while $9 \%$ patients were found to have less than $20000 / \mathrm{mm}^{3}$. The lowest platelet count and highest hematocrit were seen on fifth day of illness. Bleeding manifestations were seen in $18(32 \%)$ patients of 56 patients with platelet counts less than $40000 / \mathrm{mm}^{3}$ and $55 \%$ of the patients platelet counts below $20000 / \mathrm{mm}^{3}$. had bleeding manifestations. Bleeding manifestations were more likely with lower platelet counts.

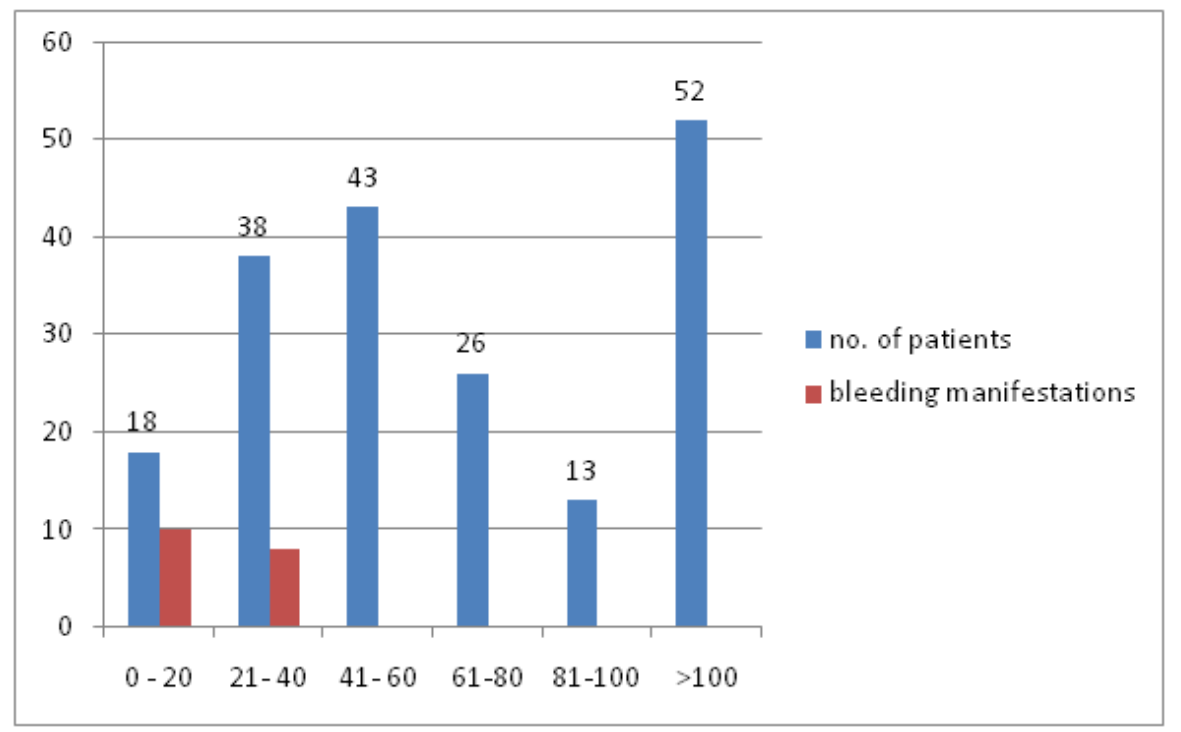

Fig.1: Showing the chart in which patients were categorized into six groups

The WBC count was low in $47 \%$ of patients, the lowest recorded was $900 \times 10^{9} / \mathrm{L}$. WBC count was below $4000 \times 10^{9} / \mathrm{L}$ in $60 \%$ of patients with platelets counts less than $40000 / \mathrm{mm}^{3}$. In 


\section{ORIGINAL ARTICLE}

this study a low hematocrit value was seen probably due to high prevalence of anemia in this part. During hospitalisation 48(25\%) patients showed elevated alanine transaminase levels and 44(23\%) patients showed elevated aspartate transaminase levels, 12 patients with elevated liver transaminases had hepatomegaly. DIC detected by clinical parameters and supported by laboratory parameters occurred in 3\% of cases, none of whom survived.

Among the 10 patients who died, seven had thrombocytopenia with platelets $<40000 / \mathrm{mm}^{3}$ while six patients were noted to have DIC with platelet $>40000 / \mathrm{mm}^{3}$

Based on clinical/ hematological diagnostic criteria, 18 patients were diagnosed to have dengue hemorrhagic fever, 6 patients were diagnosed as dengue shock syndrome and there were 10 deaths among the cases finally diagnosed as dengue fever during study period.

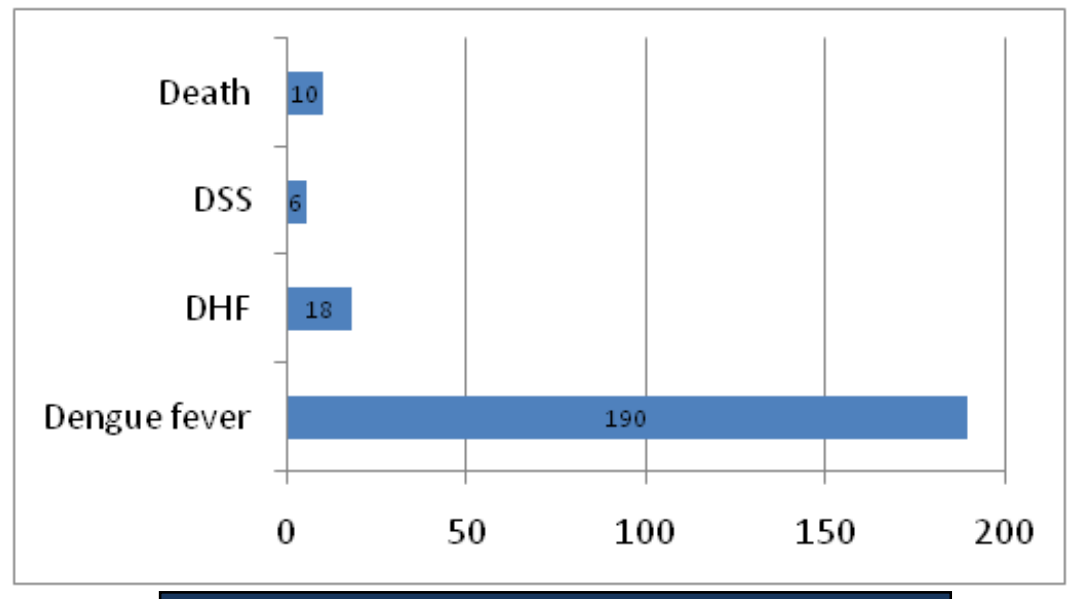

Fig.2: showing mortality due to dengue fever

Platelet rich plasma(PRP) was used in 26 patients, and total number of PRP used ranged from 4 to 15 units, they were more significantly used in patients with platelet counts less than $40000 / \mathrm{mm}^{3}$. The role of platelet transfusion is justified only in patients with active bleeding. At the most, it can be suggested that empirical transfusion may be administered in dengue patients without bleeding with a platelet count of less than $20,000 / \mathrm{mm}^{3}$ and positive tourniquet test. There was no correlation between platelet counts, age, use of intravenous fluids, or length of hospital stay.

DISCUSSION: Due to changing climate, urbanization, poor living conditions and inadequate waste management, vector borne diseases like dengue fever are becoming more common. Although vector Control programmes are launched in endemic countries, yet dengue fever has become a serious problem worldwide.India being a tropical country provides suitable weather for Aedes mosquito to grow and an increase in the disease burden has been noticed in recent years due to the rapid urbanization with unplanned construction activities and poor sanitation facilities contributing fertile breeding grounds for mosquitoes.

This study describes the clinical profile, laboratory features and outcome of DF/DHF/DSS in adult patients. In our study, $87.4 \%$ were classified as DF patients while $12.6 \%$ were classified as DHF/ DSS, the proportion of DHF is almost similar to the observation of $13.5 \%$ from Sharma et al2. In our study it is observed that males were more than female as is also reported in other studies ${ }^{3}$. 


\section{ORIGINAL ARTICLE}

Headache is one of the most common symptoms next to fever which is similar to that reported by Itoda I et al, headache was present in $90 \%$ cases. On the other hand the north Indian study by Seema A et al reported headache in only $9 \%$ of cases ${ }^{4}, 5$.In this study $45 \%$ patients had abdominal pain in contrast to $38 \%$ reported by Sharma et al $^{2}$. In our study rash was present in $27 \%$ of patients as documented in a north Indian study by Karoli $\mathrm{R}$ et al. On the other hand in a Japanese study by Itoda et al rash was more frequent in about $82 \%$ patients ${ }^{4,6}$.In a study of 62 patients in Japan, by Itodaet $\mathrm{al}^{5}$, rash was more frequent of about $82 \%$ cases $^{4}$. Hepatomegaly in this series was $14 \%$, compared to $13.5 \%$ from NimmanityaS et al 7 .

We found that only $46 \%$ cases had leukocyte count below $4000 / \mathrm{mm}^{3}$. But in study of Mittal et $\mathrm{al}^{7}$, Leucopenia was detected in $71 \%$ cases whereas Rahim MA et al found in only $4.1 \%{ }^{8,9}$.

In our study bleeding manifestations were seen in $9 \%$ of patients only, this is in contrast to the finding of Horvath from Australia ${ }^{6}$ and Sharma from India ${ }^{4}$ who reported $63 \%$ and $69 \%$ of bleeding episodes respectively2,10.

CONCLUSION:The clinical and hematological profile of dengue fever is non-specific and is similar to other viral fevers. A high index of suspicion is necessary for its diagnosis in the early stage of the disease.Bleeding manifestations are seen in patients with platelet counts less than $40000 / \mathrm{mm}^{3}$ only and chances of bleeding increases as the platelet count decreases further. Every one out of two Patients had bleeding manifestations if the platelet count is less than $20000 / \mathrm{mm}^{3}$.

\section{REFERENCES:}

1. Dhillon GPS et al Guidelines for clinical management of dengue fever, Dengue hemorrhagic fever and Dengue shock syndrome. Directorate of NVBDCP, New Delhi, 2008, p.14http://nvbdcp.gov.in/doc/clinical\%20guidelines.pdf (Accessed on 23-11-2013).

2. Sharma S. Clinical profile of DHF in adults during 1996 outbreak in Delhi, India. Dengue bulletin. 1998; 22: p. 20-27.

3. Tripathi BK, Gupta B. Experience in adult population in dengue outbreak in Delhi. JAPI. 1998; 46(3): p. 273-276.

4. Itoda I, Masuda G, Suganuma A, Imamura A, Ajisawa. Clinical features of 62 imported cases of dengue fever in Japan. American Journal of Tropical Medicine. 2006; 75(3): p. 470-4.

5. Seema A, Singh V, Kumar S, Kumar A, Dutta S. The Changing Clinical Spectrum of Dengue Fever in the 2009 Epidemic in North India: A Tertiary Teaching Hospital Based Study. Journal of Clinical and Diagnostic Research. 2012; 6(6): p. 999-1002.

6. Karoli R, Fatima J, Siddiqi Z, Kazmi KI KI, Sultania. Clinical profile of dengue infection at a teaching hospital in North India. Journal of Infection in developing Countries. 2012; 6(7): p. 551-4.

7. Nimmanitya S, Kalayanarooj. Guidelines for DHF case management for workshop on case management of DHF. 2002.

8. Mittal H, Faridi MM, Arora SK, Patil R. Clinicohematological profile and platelet trends in children with dengue during 2010 epidemic in north India. Indian J Pediatr. 2012; 79(4): p. 467-71.

9. Rahim MA, Sikder MS. Clinicopathologic manifestations and outcome of dengue fever and dengue haemorrhagic fever. Bangladesh Med Res Counc Bull. 2005; 31(1): p. 36-45. 


\section{ORIGINAL ARTICLE}

10. Horvath R, Mcbride WJ, Hanna JN. Clinical features of hospitalized patients during dengue 3 epidemic in Far North Queensland 1997-99. Dengue bulletin. 1999; 23: p. 24-29.

\section{AUTHORS:}

1. Vanamali D.R.

2. L. Venugopal

3. P. Yeshwanth

4. DilipRampure

\section{PARTICULARS OF CONTRIBUTORS:}

1. Professor, Department of General Medicine, Mamata Medical College, Khammam.

2. Associate Professor, Department of General Medicine, Mamata Medical College, Khammam.

3. Post Graduate Student, Department of General Medicine, Mamata Medical College, Khammam.
4. Professor and HOD, Department of General Medicine, Mamata Medical College, Khammam.

\section{NAME ADRRESS EMAIL ID OF THE}

\section{CORRESPONDING AUTHOR:}

Dr. Vanamali Dharma Rao, Q.No. - 7, Kinnerasani, MGH Campus, Giriprasad Nagar, Khammam, Andhra Pradesh, PIN - 507002.

Email-vdrao1@rediffmail.com

Date of Submission: 28/11/2013.

Date of Peer Review: 29/11/2013.

Date of Acceptance: 04/12/2013.

Date of Publishing: 11/12/2013 